\title{
Visual persistence and the effect of eccentric viewing, element size, and frame duration on bistable stroboscopic motion percepts
}

\author{
BRUNO G. BREITMEYER and ALYSIA RITTER \\ University of Houston, Houston, Texas
}

\begin{abstract}
Bistable stroboscopic motion percepts can be generated when two frames, each consisting of three square elements, are presented alternately at varying interstimulus intervals (ISIs). Endto-end element motion is observed at short ISIs; group motion is observed at long ISIs. We found that the ISIs at which transitions from element to group motion occurred decreased as (1) viewing eccentricity, (2) element size, and (3) frame durations increased. Since visual pattern persistence also decreases as each of these three parameters increases, we conclude that such persistence plays a role in determining which percept dominates in bistable stroboscopic motion.
\end{abstract}

One phenomenon that accompanies a briefly displayed stimulus pattern is visual pattern persistence. Two such patterns displayed in spatiotemporal sequence additionally produce the sensation of stroboscopic motion. Since pattern persistence also occurs in two- or multiple-pattern sequences (Allport, 1968; Di Lollo \& Hogben, 1985), we can ask how and to what extent persistence and stroboscopic motion are related (e.g., see Farrell, 1984). To address this question, we investigated the competing bistable stroboscopic motion percepts reported by Pantle and Picciano (1976). To produce such percepts, stimuli such as those shown in Figure 1 are presented in cyclic alternation. Frame 1 contains three equispaced and horizontally arrayed elements; Frame 2 contains the same elements displaced to the right by the center-to-center distance separating two adjacent elements. Thus, the two right elements of Frame 1 and the two left elements of Frame 2 overlap spatially. When these two frames are alternately flashed for several cycles at varying interstimulus intervals (ISIs), one can observe one of two motion percepts, depending on ISI. At short ISIs, one sees the middle two, overlapping elements as stationary and the endmost elements moving back and forth. This perception of end-to-end element motion is replaced at longer ISIs by a perception of group motion in which three elements are seen to move back and forth as a group.

In a separate study (Breitmeyer \& Ritter, in press), we showed that an overall increase of group motion-and hence a decrease of element motion-could be effected by increasing either element size or, as Petersik and Pantle (1979) had done, frame duration. In particular, the ISI at which transitions from element to group motion occurred decreased with increases in element size or frame durations. These results were interpreted in terms of the

Requests for reprints should be directed to B. G. Breitmeyer, Department of Psychology, University of Houston, University Park, Houston, TX 77004 . hypothesis that the perception of end-to-end element motion depends on the perception of stationarity of the inner two elements (Braddick, 1980; Braddick \& Adlard, 1978; Pantle \& Petersik, 1980). That is to say, over successive frames, the spatially overlapping elements are temporally integrated by the perceptual system. Moreover, we suggested that a process responsible for such integration, and hence for signaling the stationarity of the two overlapping inner elements, is pattern persistence. The longer this pattern persistence, the more likely it is that the inner two elements in successive frames are perceptually integrated. This inhibits perception of group motion but allows the perception of end-to-end element mo-

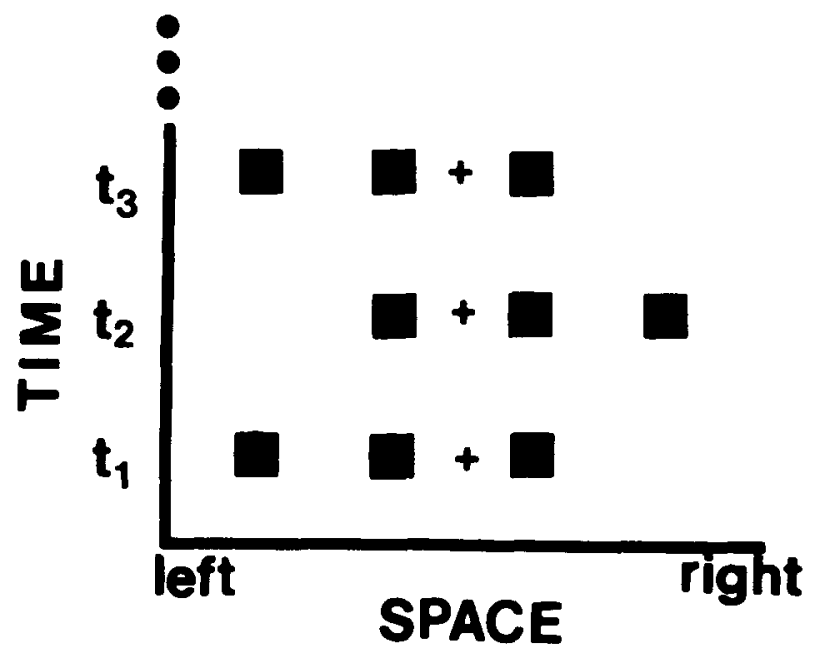

Figure 1. A schematic of the cyclic display sequence. Frame 1, containing three square elements, is presented at time $t_{1}$. After a variable ISI, Frame 2, containing the same three elements displaced rightward by the center-to-center distance separating two adjacent elements, is presented at time $t_{2}$. After the same ISI, Frame 1 again is presented at time $t_{3}$, and so on for four cycles. The fixation cross was presented, as shown, either at the level of the display sequence $\left(0^{\circ}\right)$ or $1^{\circ}$ or $2^{\circ}$ below the display sequence. 
tion. We know from prior studies (Bowen, Pola, \& Matin, 1974; Bowling \& Lovegrove, 1980; Breitmeyer, Levi, \& Harwerth, 1981; Di Lollo, 1977; Meyer \& Maguire, 1977 ) that with spatially overlapping stimuli, such as comprise the two inner elements, pattern persistence decreases as stimulus size or duration increases. Hence, as was found (Breitmeyer \& Ritter, in press; Petersik \& Pantle, 1979), one would expect the ISIs at which transitions from element to group motion occur to decrease.

In the present study, we again varied element size and frame duration as a way to vary pattern persistence. However, additionally we varied pattern persistence by varying the eccentricity of the entire motion display. Using repetitively flashed vertical square-wave gratings as stimuli (Meyer \& Maguire, 1977), Breitmeyer and Halpern (1978) found that a parafoveally centered stimulus yielded shorter measures of pattern persistence than a foveally centered one. Using a variant of a technique originally employed by Allport (1968), in which stimuli (lines or dots) are displayed in a regular spatiotemporal sequence on a cathode ray tube, both Mezrich (1984) and Di Lollo and Hogben (1985) also have shown that effective persistence decreases with eccentricity. We agree with Di Lollo and Hogben that the curtailment of pattern persistence in the parafovea obtained with a regular spatiotemporal sequence of stimuli is produced by suppression of an otherwise longer persistence found there. We further agree that under these stimulus conditions the most likely candidate for such suppression is metacontrast masking (Breitmeyer, 1984, p. 225; Breitmeyer, Battaglia, \& Weber, 1976; Breitmeyer, Love, \& Wepman, 1974; Hogben \& Di Lollo, 1984). Since the magnitude and spatial range of metacontrast masking is known to increase with eccentricity (for a review, see Breitmeyer, 1984, pp. 108-109 and 219), it follows that in a regular spatiotemporal sequence of stimuli in which one stimulus is followed closely in time and space by another, pattern persistence ought to be curtailed as stimulus eccentricity increases. On the basis of this analysis, we predict that as our bistable motion display is viewed at greater eccentricities, progressively less element motion and, hence, more group motion ought to be observed.

\section{METHOD}

\section{Subjects}

The 2 authors and 4 undergraduate students at the University of Houston served as subjects. All subjects had normal or correctedto-normal vision, and all 4 undergraduates; besides having had no prior experience in making psychophysical judgments, were naive as to the purpose of the experiment.

\section{Stimulus and Apparatus}

All stimuli, presented via a four-channel Gerbrands Model T-4A Harvard tachistoscope, were viewed binocularly at a distance of $81 \mathrm{~cm}$. The stimuli consisted of equispaced elements as shown in Figure 1. The elements were gray squares $\left(15.7 \mathrm{~cd} / \mathrm{m}^{2}\right)$ on a white surround $\left(30 \mathrm{~cd} / \mathrm{m}^{2}\right)$. The center-to-center distance between elements was maintained at a constant $1.2^{\circ}$. However, the sizes of the square elements could be either $.2^{\circ} \times .2^{\circ}$ or $.7^{\circ} \times .7^{\circ}$. For convenience, we refer to these sizes as small or large. Frames 1 and 2 were each displayed on a separate channel of the tachistoscope, as was the fixation field, which also served as the blank interval between successive frames. The fixation field's luminance was $30 \mathrm{~cd} / \mathrm{m}^{2}$. For foveal fixation, the fixation cross, as shown in Figure 1, fell halfway between the inner two, spatially overlapping elements of the total display sequence. For eccentric stimulus presentations, the fixation cross fell either $1^{\circ}$ or $2^{\circ}$ directly below its position in Figure 1. Frame durations were set at 50 or $200 \mathrm{msec}$.

\section{Procedure}

We employed a four-factor $(2 \times 2 \times 3 \times 10)$ design. One factor consisted of the two element sizes; the second, of the two frame durations; the third, of the three display eccentricities; and the fourth, of 10 ISIs-ranging, in 10-msec steps, from 10 to $100 \mathrm{msec}-$ separating the alternating frames. For each subject, data were collected during four sessions spanning about 2 weeks. In each of the four sessions, three 100-trial blocks were run per subject. Across the three blocks, the element size and frame durations were kept constant; however, each of the three blocks was devoted to one of the three display locations. The order of display eccentricities was randomized within a session; and element size and frame duration were cross randomized over the four sessions. Within a block of 100 trials, 10 trials were devoted to each ISI. Before each series of 100 trials, the subjects viewed a blank $30-\mathrm{cd} / \mathrm{m}^{2}$ field for $3 \mathrm{~min}$. A trial consisted of four cycles of the stimulus sequence (Frame 1-ISI-Frame 2-ISI) with about $10 \mathrm{sec}$ elapsing between trials. The four undergraduate subjects also were given one session that served to familiarize them with the task and give them practice in making psychophysical judgments. On each trial, the subjects were asked to classify their responses according to whether they perceived group motion or element motion.

\section{RESULTS AND DISCUSSION}

Figure 2 displays the percentage of group movement as a function of ISI. The curve parameters are the display eccentricities. The left and right panels show the results obtained with small and large elements, respectively; the upper and lower panels show the results obtained with 50- and 200-msec frame durations, respectively. In all cases, the percent of group movement increased with ISI. This trend, reported in many prior studies of bistable stroboscopic motion, is reflected in a significant main effect of ISI $[F(9,600)=76.30$, $p<.0001]$. Also evident in Figure 2 is the increasing percentage of group movement reports as the display eccentricity increased $[F(2,600)=56.53, p<.0001]$. This trend is consistent with our persistence hypothesis: increases of display eccentricity are accompanied by decreases of visual persistence, hence by a decrease of element motion and a concomitant increase of group movement. Furthermore, as we have demonstrated elsewhere (Breitmeyer \& Ritter, in press), increasing the element size $[F(1,600)=110.03, p<.0001]$ or the frame duration $[F(1,600)=488.97, p<.0001]$ increases the overall percentage of group movement. Again, these trends are consistent with our persistence hypothesis, inasmuch as increases of element size and frame duration decrease persistence and thus favor the perception of group movement. 
SMALL

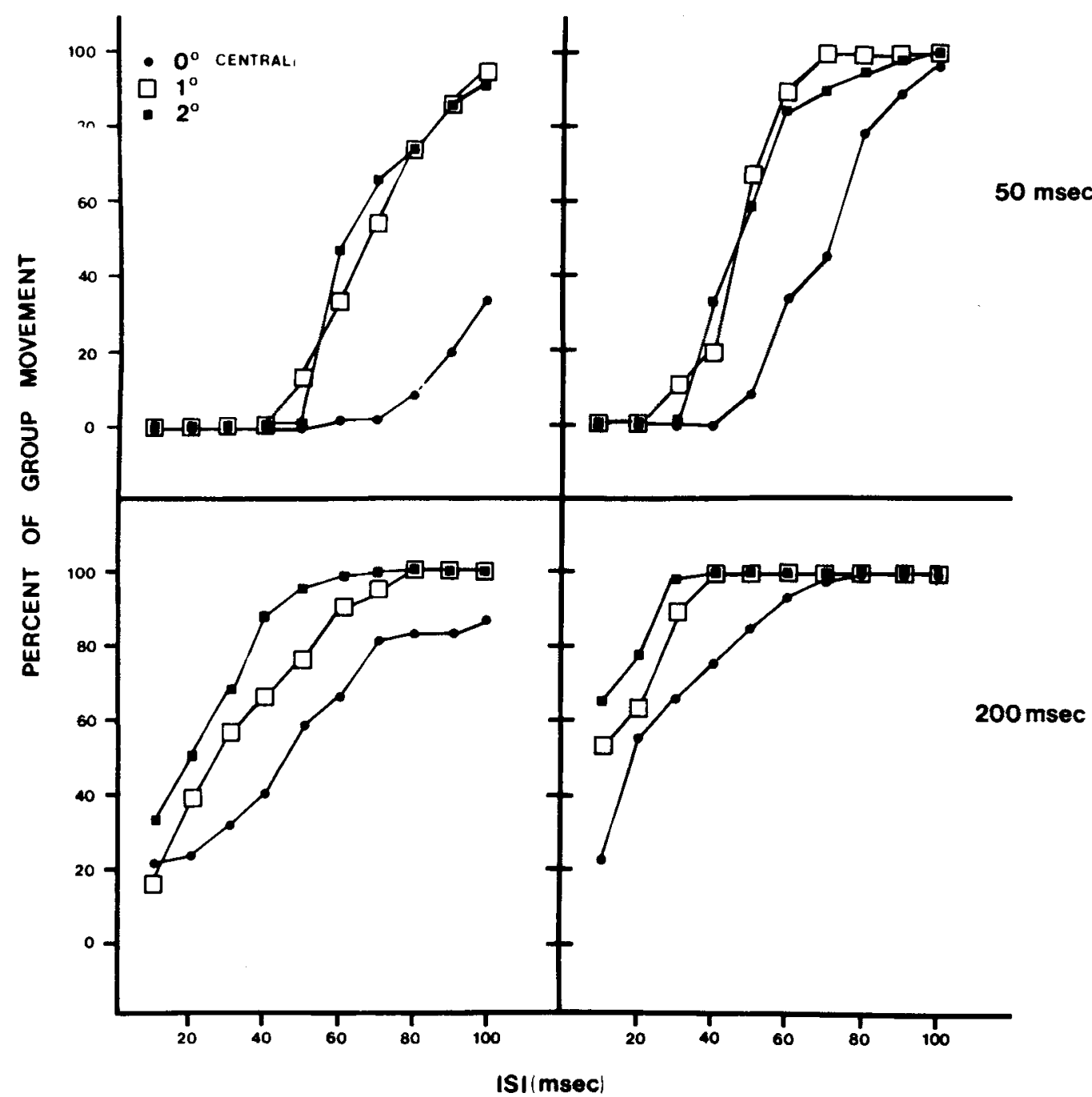

Figure 2. The percentage of group movement reported as a function of ISI for small (left panels) and large (right panels) elements and for 50-msec (upper panels) and 200-msec (lower panels) frame durations. In each panel are shown results obtained at each of the three display eccentricities as indicated at the upper left of the figure.

Of the possible two-way interactions, only those between element size and frame duration $[F(1,600)=5.29$, $p<.01]$, between element size and display eccentricity $[F(2,600)=4.58, p<.05]$, and between frame duration and ISI $[F(9,600)=11.83, p<.01]$ were statistically significant. In regard to the first of these two-way interactions, Figure 2 shows not only that the percent of group movement increases as frame duration increases, but also that this trend is stronger for small than for large elements. This result again is in agreement with our persistence hypothesis. Bowling and Lovegrove (1980) demonstrated that visual persistence of grating stimuli is affected interactively by spatial frequency and duration. They found, in agreement with our results and interpretation, that increases of duration decreased visual persis- tence more when high-spatial-frequency gratings (small patterns) were employed than when low-frequency ones were used. Hence, as we found, with smaller patterns one would expect a greater increase of the percentage of group movement as frame duration increases. As to the second significant two-way interaction, one can see from Figure 2 that the increase of the percentage of group movement as display eccentricity increases is again more apparent for small- than for large-element displays. According to our hypothesis, this occurred because increases of eccentricity decreased visual persistence more for the smallthan for the large-element displays. Independent studies of visual persistence corroborating or elaborating on this trend and interpretation are yet to be performed. Regarding the third significant two-way interaction, Figure 2 also 
shows that the transition from a greater preponderance of element motion to one of group movement as ISI increases occurs at ISIs that are lower for the 200-msec than for the 50-msec frame duration. Again, according to our hypothesis, one would expect the longer frame durations to yield shorter persistence and thus to produce more reports of group movement at shorter ISIs.

Inspection of Figure 2 also reveals that this latter effect of frame duration on the transitional ISIs is more pronounced with small- than with large-element displays. This trend is reflected in a significant three-way interaction between element size, frame duration, and ISI $[F(9,600)=4.53, p<.005]$. Finally, there was a significant three-way interaction between element size, display eccentricity, and $\operatorname{ISI}[F(18,600)=3.45, p<.005]$. As can be seen in Figure 2, the change of the transitional ISIs to smaller values as display eccentricity increases is more pronounced when small than when large elements were used. These two significant three-way interactions basically are elaborations of the significant two-way interactions between element size and frame duration and between element size and display eccentricity. The greater increases in the percentage of group movement for smaller elements of longer duration, on the one hand, and for smaller elements of greater eccentricity, on the other, are more particularly realized by a shift of the transitional ISIs to lower values. The other two three-way interactions and the four-way interaction were not statistically significant.

\section{GENERAL DISCUSSION}

Our main concern was with how display eccentricity, within the framework of the persistence hypothesis, affected the transition from element to group movement as ISI increased. The results of the eccentricity manipulation are consistent with the hypothesis that visual persistence decreases with eccentricity, a finding independently reported by Mezrich (1984) and by Di Lollo and Hogben (1985). Di Lollo and Hogben, however, additionally argue that the curtailment of visual persistence with eccentricity occurs only when the contours or edges of successive stimuli are spatially sufficiently close to allow metacontrast suppression of the response persistence to a preceding stimulus by a succeeding stimulus. We also subscribe to this explanation (see also Breitmeyer, 1984, p. 225), and we note its relevance in our study since the contours of the two overlapping inner elements of the display sequence were spatially as close as possible and thus should act as optimal metacontrast masks (Matin, 1974).

Secondarily, we found that the percentage of group movement increased also when element size or frame duration increased. Again, these results are consistent with our persistence hypothesis. However, although the latter effects of frame duration have been reported independently by Petersik and Pantle (1979) and by Breitmeyer and Ritter (in press), the former effects of element size found here and by Breitmeyer and Ritter were not confirmed in a study reported by Petersik and Grassmuck (1981). These investigators reported that the ISI at which transitions from element to group motion occurs tends to increase as the spatial frequencies composing each frame of the alternating displays decrease. On the basis of our persistence hypothesis and the finding that persistence decreases as spatial frequency decreases (Bowling \& Lovegrove, 1980; Breitmeyer et al., 1981; Meyer \& Maguire, 1977), one would expect the opposite result, namely, that the transitional ISI decreases as spatial frequency decreases.

A look at individual subjects' data in the present study and in our prior work (Breitmeyer \& Ritter, in press) indicates that the effects of element size that we report hold not only across but also within subjects. Hence, we cannot attribute our results to the extreme or aberrant performance of one or a few subjects. A more likely candidate may be the fact that, in the present study and in that of Breitmeyer and Ritter (in press), a procedure was employed which differed from that used by Petersik and Grassmuck (1981). We used a modified version of the method of constant stimuli, whereas the latter investigators used a method of ascending and descending limits to bracket the transitional ISI at which reports of group and element motion are equiprobable. By systematically increasing the ISI values in the ascending case or decreasing them in the descending case, selective adaptation effects, reported by Petersik and Pantle (1979), may have been introduced which were absent in the present and Breitmeyer and Ritter's (in press) studies.

However, although this discrepancy may require further investigation along lines suggested by the above analysis, several other results reported in prior studies dovetail nicely with our persistence hypothesis. For instance, both Braddick and Adlard (1978) and Petersik and Pantle (1979) showed that the percentage of group movement increased as the luminance of the blank ISI field increased. This result has been explained in terms of masking by light (Braddick, 1973, 1980; Petersik \& Pantle, 1979), and our explanation in terms of visual persistence concurs with this view insofar as one can view masking by blank fields as a form of transient light or dark adaptation (Breitmeyer, 1984, chap. 2; Crawford, 1947). We know that visual persistence decreases with the level of light adaptation (for a review, see Breitmeyer, 1984, chap. 3). Hence, the use of brightly illuminated blank ISIs, by decreasing and curtailing pattern persistence, should increase reports of group relative to element motion. Supporting this interpretation is Petersik and Pantle's (1979) additional finding that the ISI at which one obtains transitions from element to group motion increased with dark-adaptation time, that is, the time after the offset of a bright light-adapting field. Since pattern persistence increases with dark adaptation, one would, according to our hypothesis, expect element motion to prevail at increasingly longer ISIs as the course 
of dark adaptation proceeds; hence, the transition from element to group motion also should occur at progressively higher ISIs.

Another interesting finding is that element motion is greatly curtailed (Braddick \& Adlard, 1978) or eliminated (Pantle \& Picciano, 1976) across ISIs when the alternating frames are presented dichoptically. According to our hypothesis, one possible factor is that pattern persistence is curtailed more severely with dichoptic presentations. This would make sense in that metacontrast masking, which gives rise to the suppression of pattern persistence, is more effective dichoptically than monoptically (Schiller \& Smith, 1968).

Despite the concordance of these findings with our persistence hypothesis, one additional finding reported by Petersik and Pantle (1979) seems to be at odds with it. We know that pattern persistence measured with grating stimuli increases as the contrast of the grating decreases (Bowling \& Lovegrove, 1981). Hence, according to our persistence hypothesis, elements with a lower contrast, by producing longer pattern persistence, ought to produce more element motion or, alternatively, less group motion. Petersik and Pantle (1979) reported the opposite result; as stimulus contrast decreased, the percentage of group motion tended to increase rather than decrease across ISIs. However, it should be mentioned that, in Petersik and Pantle's (1979) study, the contrast of the elements was varied by decreasing the intensity of the elements from 1.49 to $0.30 \mathrm{~mL}$ relative to a nonchanging uniform background of $1.65 \mathrm{~mL}$. We know also from the work of Bowen et al. (1974) that the duration of visual persistence varies inversely with stimulus intensity. Hence, by using increasingly less intense elements in order to increase their contrast relative to a uniformly brighter background, Petersik and Pantle's (1979) procedure of varying element contrast may have led to an increase in persistence as element intensity decreased. A consequence of this analysis is that when element contrast is increased by increasing rather than decreasing its intensity relative to a uniform background, one should obtain the trend predicted by our hypothesis, which is opposite to that found by Petersik and Pantle (1979). We currently are investigating this possibility.

Finally, insofar as recent theories of visual masking and persistence (Breitmeyer, 1984; Breitmeyer \& Ganz, 1976; Matin, 1975; Weisstein, Ozog, \& Szoc, 1975) have involved properties of and interactions between sustained and transient channels, the role of these channels is also implicated in studies of bistable stroboscopic motion. In fact, Petersik and Pantle (1979) suggested that response properties of processes mediating element and group motions parallel those of sustained and transient channels, respectively. We agree with this suggestion and frame it within our persistence and masking hypotheses in the following way. Insofar as stronger pattern persistence relies on a stronger sustained channel response (Breitmeyer, $1980,1984)$, one would expect more element motion when the sustained channels are more active. Conversely, insofar as sustained pattern persistence is suppressed by strong transient activity, one would expect group motion to increase as transient activity becomes increasingly dominant.

\section{REFERENCES}

Allport, D. A. (1968). Phenomenal simultaneity and the perceptual movement hypothesis. British Journal of Psychology, 57, 395-406.

Bowen, R. R., Pola, J., \& MAtin, L. (1974). Visual persistence effects of flash luminance, duration, and energy. Vision Research, 14, 295-303.

Bowling, A., \& Lovegrove, W. (1980). The effects of stimulus duration on the persistence of gratings. Perception \& Psychophysics, 27, 574-578.

Bowling, A., \& Lovegrove, W. (1981). Two components of visual persistence: Effects of orientation and contrast. Vision Research, 21, 1241-1251.

BRADDICK, O. (1973). The masking of apparent motion in random-dot patterns. Vision Research, 13, 355-369.

BRADDICK, O. (1980). Low-level and high-level processes in apparent motion. Philosophical Transactions of the Royal Society (London), 290B, 137-151.

BradDICK, O., \& ADLARD, A. (1978). Apparent motion and the motion detector. In J. C. Armington, J. Krauskopf, \& B. R. Wooten (Eds.), Visual psychophysics and psychology. New York: Academic Press.

BREITMEYER, B. G. (1980). Unmasking visual masking: A look at the "why" behind the veil of the "how." Psychological Review, 87, 52-69.

BREITMEYER, B. G. (1984). Visual masking: An integrative approach. New York: Oxford University Press.

Breitmeyer, B. G., Battaglia, F., \& Weber, C. (1976). U-shaped backward contour masking during stroboscopic motion. Journal of Experimental Psychology: Human Perception \& Performance, 2, 167-173.

BreitMEYER, B. G., \& GANZ, L. (1976). Implications of sustained and transient channels for theories of visual pattern masking, saccadic suppression, and information processing. Psychological Review, 83, 1-36.

BreitMeyer, B. G., \& HalPERN, M. (1978, November). Visual persistence depends on spatial frequency and retinal locus. Paper presented at the annual meeting of the Psychonomic Society, San Antonio, TX.

Breitmeyer, B. G., LeVI, D. M., \& HARWERTH, R. S. (1981). Flickermasking in spatial vision. Vision Research, 21, 1377-1385.

Breitmeyer, B. G., Love, R., \& WePMaN, B. (1974). Contour suppression during stroboscopic motion and metacontrast. Vision Research, 14, 1451-1456.

Breitmeyer, B. G., \& Ritter, A. (in press). The role of visual persistence in bistable stroboscopic motion. Vision Research.

Crawford, B. H. (1947). Visual adaptation in relation to brief conditioning stimuli. Proceedings of the Royal Society (London), 129B, 94-106.

Di LolLo, V. (1977). Temporal characteristics of iconic memory. $\mathrm{Na}$ ture, 267, 241-243.

Di Lollo, V., \& Hogben, J. H. (1985). Suppression of visible persistence. Journal of Experimental Psychology: Human Perception \& Performance, 11, 304-316.

FARRELL, J. E. (1984). Visible persistence of moving objects. Journal of Experimental Psychology: Human Perception \& Performance, 10, 502-511.

Hogben, J. H., \& Di Lollo, V. (1984). Practice reduces suppression in metacontrast and in apparent motion. Perception \& Psychophysics, 35, 441-445.

Matin, E. (1974). Saccadic suppression: A review and analysis. Psychological Bulletin, 81, 899-917.

Matin, E. (1975). The two-transient (masking) paradigm. Psychological Review, 82, 451-461. 
Meyer, G. E., \& Maguire, W. M. (1977). Spatial frequency and the mediation of short-term visual storage. Science, 198, 524-525.

MezrICH, J. J. (1984). The duration of visual persistence. Vision Research, 24, 631-632.

PANTle, A. J., \& Petersik, J. T. (1980). Effects of spatial parameters on the perceptual organization of a bistable motion display. Perception \& Psychophysics, 27, 307-312.

Pantle, A., \& Picciano, L. A. (1976). A multistable movement display: Evidence for two separate motion systems in human vision. Science, 193, 500-502.

Petersik, J. T., \& Grassmuck, J. (1981). High fundamental spatial frequencies and edges have different perceptual consequences in the 'group/end-to-end' movement phenomenon. Perception, 10, 375-382.
Petersik, J. T., \& PANTle, A. J. (1979). Factors controlling the competing sensations produced by a bistable stroboscopic display. Vision Research, 19, 143-154.

Schiller, P. H., \& Smith, M. C. (1968). Monoptic and dichoptic metacontrast. Perception \& Psychophysics, 3, 237-239.

Weisstein, N., OzoG, G., \& Szoc, R. (1975). A comparison and elaboration of two models of metacontrast. Psychological Review, 82, 325-343.

(Manuscript received December 13, 1985; revision accepted for publication April 9, 1986.) 